\title{
The Application of Domestication and Foreignization Translation Strategies in English- Persian Translations of News Phrasal Verbs
}

\author{
Ebrahim Davoudi Sharifabad (Corresponding Author) \\ School of Languages, Literacies, and Translation, Universiti Sains Malaysia, 11800 Universiti Sains Malaysia, Penang, \\ Malaysia \\ Mojde Yaqubi \\ Young Researchers Club, Hamedan Branch, Islamic Azad University, Hamedan, Iran \\ Tengku Sepora Tengku Mahadi \\ School of Languages, Literacies, and Translation, Universiti Sains Malaysia, 11800 Universiti Sains Malaysia, Penang, \\ Malaysia
}

\begin{abstract}
Since we live in an increasingly globalized world, we are definitely more well-informed about the world happenings through various mediums of globalization such as internet, news agencies, news channels, etc. Here lies the important and remarkable role of translation as a medium of conveying messages and transferring information. If a news piece is translated problematically, it may have bad effects on people's thinking about a certain country or it may lead to misunderstanding and misjudgment. Therefore, to produce translations as properly as possible, especially in cultural and cross-cultural aspects of translation which are abundant in news texts, the translators need to apply effective translation strategies. Domestication and foreignization translation strategies are two important strategies of translation in rendering phrasal verbs in news from a source-text language to a culture-specific target-text one. The authors of this study have applied these strategies of translation to English-Persian phrasal verbs in news texts to investigate whether EnglishPersian translators tend to domesticate the news headlines or foreignize them. The news containing phrasal verbs was analyzed based on the ones from different news agencies and websites. First, some news containing phrasal verbs is analyzed, then the English translations were compared and contrasted. As the results of the study showed, English to Persian translators tend to apply the domestication strategy more frequently. It was concluded that since culture-specific terms and words are difficult to be understood in the target language, the translators mostly tend to localize or domesticate them. This research is helpful in journalistic translation studies, since it focuses on the important features of phrasal verbs as culture-specific and context-bound terms with respect to translation strategies.
\end{abstract}

Index Terms - translation, journalistic translation, news, phrasal verbs, domestication and foreignization translation strategies

\section{INTRODUCTION}

Translation activities in the media in general and in the press in particular are eagerly needed owing to the rapidity broadening of world-wide communication between the nations of the globe. Translation is likened to a bridge across language and culture barriers. In translating news, proper and high quality translation is essential and even crucial, since news is distinctive text types that belong to journalistic texts. Journalistic translation, mostly from English into different languages, is of eminent significance because it is regarded as a powerful force and a noticeable feature that penetrates various aspects of the target language press (Aal, 1994, p. 85).

The journalistic translator needs not only to have a wide knowledge of the subject matter, but also he/she has to be aware of the different implications and connotations of the cultural and political expressions used in the news phrasal verbs. News phrasal verbs make proficient use of figurative expressions that mirror the culture of a particular society and its ideologies, traditions and art. Since one the functions of news phrasal verbs is perhaps to quickly and briefly rivet the reader's attention, they contain such rhetorical figurative expressions i.e. culture-loaded words.

The deployment of different political words and expressions in the news texts makes their translation challengeable because the literal translation approach often results in foreignizing the expression, whereas the idiomatic method of translation results in the complete naturalness of the expression. In some cases, however, literal translation succeeds in rendering the cultural aspects of the foreign expression due to certain points of similarities between the source culture and the target culture. 


\section{STATEMENT OF THE PROBLEM}

News phrasal verbs are considered to be of special value in the press; a value that should be taken into special consideration by translators. Their value stems from the fact that they help the translator get the right message across. Moreover, their style is extraordinary and characteristic because of the deft employment of figures of speech that change ordinary language style into a distinctive one.

News phrasal verbs pose a challenge for translators for their translation is most of the time involves problematic areas. The translator should have a rich cultural background of his own culture in the first and foremost place. He/she should also have to be aware of the socio-cultural features of the target text that is peculiar to a certain society. Disqualified translation of culture-specific news phrasal verbs results in misapprehension as to the content of a piece of news or serious misjudgments about someone or something. Misleading information due to poor translation could give a wrong idea or impression or even distort the receiver's image of a whole nation.

Translators then should make good use of different translation strategies in various cultural settings between diverse languages and cultures in the world. Cultural implications and connotations of rhetorical devices used in news headlines should be taken into special account by translators, as well. There is obviously an undeniable loss in rendering the image of a cultural source-text expression that should be avoided by translators in the process of translating which is a communicative cross-cultural activity whose ultimate aim is to achieve human interaction across language and culture boundaries.

\section{A. Phrasal Verbs}

Hori, Tabata and Kumamoto (2009) defined phrasal verbs as a combination of a preposition and a verb such as "put up". Quirk et.al (1985) refered to phrasal verbs as "idiomatic combinations which behave as a single unit". They differentiated such verbs from "free combinations in which the verb and the adverbs have distinct meanings" (p. 1152).

Hart (2009) contended that some phrasal verbs are not difficult to understand the ones such as sit down or come in, while some others are not easy to understand since they are idiomatic. "Idiomatic means that there is no way to know what the verb and particle mean together by knowing what the verb and particle mean separately. For example, every beginning-level student learns what the words call, run, off and out mean, but that does not help the student to know that call off means cancel or run out means use all of something" (p.vi). Being idiomatic has made phrasal verbs difficult to understand. They are used in everyday speaking or daily newspapers. Therefore, understanding their meanings and rendering them in a target language is a tough and delicate task.

\section{B. Translating Phrasal Words}

According to Newmark (1983) the mistranslation of phrasal words is the translators' unawareness of phrasal words "functions". They function as:

(a) Less formal (but sometimes neutral, as in 'go out) (b) less pompous (c) more forceful, than their non-phrasal equivalents. The particles of phrasal words are often intensifiers, emphasizing thoroughness or completion ('use up', 'sleep in', 'pick out')... English phrasal verbs show up semantic gaps in in most foreign languages, and therefore they are invaluable to a translator into English and frustrating to a translator from English... Potentially, phrasal verbs are either physical/behavioral ('put on clothes') or mental/emotional ('put on an air of'), and often have three or four additional meanings in both categories. ('put on' has nine.) They respond a popular social need for simple colloquial or informal language, and in a climate of more or less real democracy meet less prejudice say fifty years ago. (pp.30-31).

\section{Culture and Translation}

The process of translating involves two different languages which are the carriers of their respective cultures; therefore it is not only a process of transference between languages but also a communication between diverse cultures (Li and Xia 2010).

Nida (1964, p. 244) pointed out that "the larger cultural context is of utmost importance in understanding the meaning of any message; for words have meanings only in terms of the total cultural setting". Cultural gaps between the source and the target language have always been a considerable issue for translators to be aware of when they render literal and/or figurative meanings of words since those meanings have various connotations and implications in their different cultural settings. To translate is to compare cultures and language as a tool of translation is an intrinsic part of a culture (Nord 2001). Therefore, in order to reach a better intercultural communication, the translator's duty as a medium of cultural exchange has to be better fulfilled (Chen 2010).

Cultural issues in the translation of English news headlines such as the unique and deep connotations of the figurative expressions that are heavily used in headlines; i. e. culture-loaded words should be taken into careful consideration by the translator in order to make target readers appreciate exotic cultures and recognize the difference among the distinct cultures of the globe. It is worth mentioning here that the need for translation stems from the need to communicate. Therefore, if it were not for those cultural differences, translation as a social exchange process and a communication tool would not emerge and develop. Last but not least, as Li and Xia put it "The openness and permeability of culture has provided translatability for the translation" (p. 698).

\section{The Functional Theory of Translation}


Since translation is regarded as a kind of communicative behavior, different communicative functions may require different translation strategies. Nord (2001) went on saying that "if the purpose of translation is to keep the function of the text invariant, function markers often have to be adapted to target culture standards" (p.45). Nord defined the process of translation as a target-culture substitute, whose aim is to function for the sake of the target receiver, for a source-culture text. Therefore, within the framework of functionalism, translators should be aware of the relationship between the target text and its audience which is supposed to be similar to the one that exists between the original text and its readers. On the other hand, translators should consider the relationship between the two corresponding texts; i. e. the target text and the source text. In brief, as Nord (p. 39) believes that "translators should be guided by the function they want to achieve by means of their translation and be able to use the intended communicative function of the target text as a guideline."

In a similar vein, Nida (1964) made a clear-cut distinction between two types of equivalence in translation, namely formal and dynamic (or functional) as basic translation orientations. 'Formal equivalence' focuses on the ST structure, in other words, the faithfulness of the message itself, in both form and content. While, full naturalness of expression is achieved only by 'dynamic equivalence'. Therefore, "the message has to be tailored to the receptor's linguistic needs and cultural expectations" (Munday 2001, p. 42).

To achieve such complete naturalness of expression, Nida (1964a, pp. 167-8) went on to say that adaptations of grammar, of lexicon and of cultural references are essential. In his own perspective, the ST language should not interfere with the TT language; and this is done by minimizing the foreignness of the ST setting. (pp.167-8) Producing a similar response is the basis of Nida's 'the principle of equivalent effect'. It is in fact one of the four basic requirements that Nida stressed in his theory of dynamic equivalence, according to which, he considers the receivers of the TT along with their cultural expectations as key factors in any successful translation process (Munday 2001).

\section{Domestication and Foreignization Theory}

"Domestication and foreignization are two basic translation strategies which provide both linguistic and cultural guidance" (Yang 2010, p.1) for translators in rendering culture-specific source texts into parallel target texts. Domestication is the type of translation which involves minimizing the source-text foreign elements to the targetlanguage cultural values (Munday 2001). Foreignization, on the other extreme, involves retaining the foreigness of the original-language text (Shuttleworth \& Cowie, 1997). In Venuti's perspective, the foreign elements should be highlighted by the translator to register the linguistic and cultural difference of the foreign text (Venuti 1995). Whereas Nida, who is regarded as the representative of those who favor domestication, sees domestication as the strategy that seeks to achieve complete naturalness of the expression by means of 'dynamic equivalence'. Therefore, 'the message has to be tailored to the receptor's linguistic needs and cultural expectations" (Munday 2001, p. 42).

The debate over domestication and its extreme method of foreignization has strongly influenced by and later developed from the time-worn controversy over literal and free translation methods (Dongfeng 2002). Literal and liberal translations are two techniques adopted to tackle the linguistic form, whereas domestication and foreignization transcend linguistic boundaries. They are more concerned with the two cultures. The former replaces the source culture with the target culture and the latter preserves the differences in both linguistic presentation and cultural connotation of the source culture (Yang, 2010).

Domestication and foreignization came out to answer the question of how to bridge the gulf that had grown between the writer of the source-text which is written in a language that is very culture-bound and the target-text writer (Munday, 2001) Therefore, the time-worn debate has moved beyond the limits of word-for-word and sense-for-sense to a readeroriented translation versus a writer-oriented one (Schleiermacher, 1813/1992 quoted in Munday, 2001) In order to achieve the reader-oriented translation strategy, the translator should adopt a 'naturalizing' method of translation. The translator, on the other hand, should apply an 'alienating' translation method if he/she seeks to achieve the writeroriented strategy (Venuti, 2001).

\section{Nida's Formal and Dynamic Theory of Equivalence in Translation}

As a Bible translator advocating Christianity, Nida (1964) made a major contribution to the science of translation and translating religious texts. Nida's theory of equivalence was a reform in the world of translation studies. Nida proposed two basic types of equivalence: 1) formal equivalence and 2) dynamic equivalence. "Formal equivalence focuses attention on the message itself, in both form and content ...." (p.159). The one that is concerned with the message in the receptor language should match as closely as possible the different elements in the source language (Nida, 1964 as cited in Munday).

Therefore, it can be concluded that formal equivalence is intensely based on the source language text structure which plays a key role in determining accuracy and correctness in translation. The use of scholarly footnotes to let students gain close access to the language and customs of the source culture is of marked characteristics of formal equivalence (Munday, 2001).

In formal-equivalence based type of translation, the choice of correspondences are as "poetry to poetry, sentence to sentence and concept to concept". Based on this formal orientation, the message in the receptor language should match closely different elements in the source language text. It means that the criterion of determining the accuracy and correctness of translation is comparing the message in the receptor culture with the same in the source culture. Such a formal kind of translation, which "typifies the structural equivalence", is called "gloss translation". "A gloss translation 
of this type is designed to permit the reader to identify himself as fully as possible with a person in the source-language context, and to understand as much as he can of the customs, manner of thought, and means of expression " (Hatim and Munday, 2004, p.167).

In contrast, a translation which is based on dynamic equivalence is the one attempting to produce a dynamic rather a formal equivalence. Such a translation is mainly based on the equivalent effect principle. This kind of translation is not concerned with matching the message in the source language to the message in the target language, but is to produce exactly the same effect on the receptor language reader. Nida (1964) stressed that "the relationship the receptor and message should be substantially the same as that which existed between the original receptors and the message. Dynamic equivalence is the closest natural equivalent to the source-language message" (p.159).

To Nida (1964), a dynamic-equivalence based type of translation is that which does not sound foreign to the reader and is quite natural to him/her. He maintained that the translation is successful while the equivalent response is achieved, and to achieve equivalent response, correspondence in meaning must have priority over correspondence in style (Munday, 2001). The most outstanding contribution of Nida (1964) to translation was that by introducing formal and dynamic equivalence, he moved toward the reader, i.e. his approach to translation was receptor-based.

\section{News Translation}

As one of the text types and genres of translation, news translation has got its own specifications. According to Chesterman (2000), there are two significant specifications or as he calls 'constrains' in translating news. They are 'time and deadline and a multitude of issues'. "In order to cope with these two main constraints, the translator of the text for the news media must have efficient methods of information retrieval, must be able to solve comprehension and translation problems quickly, must be capable of making fast decisions, and must have efficient translation strategies" (pp. 109-110).

Gambier (2006) believed that there are three important issues mirroring in translating news, since these features are indispensable features of news texts per se. They are as 'A call for new research topics, Hyperbole and understatement and Framing'. Gambier explains these three features as:

Topics such as gay marriage in Spain, abuse of women and children and divorce in the Republic of Ireland, contraception and abortion in Poland, etc., are important, not only to understand the socio-cultural shifts in the systems of values and ideals in these countries concerning gender, sexuality, new female and male bodily identities, but also to uncover how the foreign press reports and articulates these changes with its own values and ideals, with its own linguistic representation and its own categorisation, how newspapers perform their public opinion elsewhere? Was it because hyperbole is not used with the same frequency and was translated literally that in many places Bush's statements were taken as false, considered as exaggerations or simply lies, or not credible? (pp.9-11)

To explain the second factor, Gambier posited that hyperbole and understatement are two linguistic and ideological factors related to translating press since they are two tools of 'manipulation'. As a 'rhetorical device', hyperbole is "used to highlight, intensify, and amplify selected elements of the image of reality, seems to be extremely pervasive in communication of any kind. It is traditionally associated with literature but it can in fact be present in most types of linguistic activity, from everyday interactions to carefully designed political propaganda" (p. 10). Gambier stated that both hyperbole and understatement are mostly literary devices that affect the readers' perceptions and the reality, and are used differently in different cultures.

As for the third factor, frame, Gambier mentioned that by frame, it is meant that "the media provide frames of reference, or highly stereotyped representations of specific situations, to make the event accessible to the public. And they shape other kinds of frames - the ones that the audience, the individuals use when interpreting information about events" (p. 11). The frame includes 'stereotypical scenarios, routines, and beliefs' which are based on 'expectations in a given social situation'.

Vybíralová (2012), maintained that the main features of journalistic translation are "limitations of time and space, the strive to produce readable texts, media's general tendency towards manipulation, and their by-products - textual modifications" (p. 18). Time and space constraints are two factors affecting the journalistic translation. Since journalistic texts live in a short period of time and should be broadcasted as soon as possible and there is a limitation in space for journalists and translators, , the translators have to be fast enough in rendering the source text into target text and they need to consider the apace limitations. Due to these constraints, to make good translations, translators may resort to making many 'modifications' such as shortening the long paragraphs and texts, skipping and deleting some words and sentences, or 'summarizing'( $p 19)$.

Another important feature of journalistic texts and consequently journalistic translation, is the text readability. As very crucial characteristics of newspapers and journals are attracting readers' attention and being readable as quick as possible, readability seems to be the favored and vital concept lying behind the act of translating (p. 19). Manipulation or any change in the meaning can also be another important factor in translating press. Vybíralová rendered manipulation as "distortion of meaning". "In fact, it could be argued that the first occurrence of manipulation starts with the selection of material to be translated; every day, there are a number of events and opinions presented in the source journal but only one or two will appear in the target media. But this is what happens in journalism in general as both source and target readership is the -recipient of selected information only" (p. 20). 


\section{Methodology}

The method followed in this study is descriptive and the researchers, after finding and analyzing the instances of phrasal verbs, examined the Persian translation of the related samples. It should be noted that all the analyzed data are basically applicable to the present sentence. Each phrasal verb is translated based on the sentence and context it is mentioned in. However, each of these phrasal verbs may have another meaning in another sentence and context. Through a descriptive method, the researchers attempted to describe and interpret the status of phenomena. Thus, this research is a comparative study of phrasal verbs in English news and its Persian translations. The translation strategies to be examined in the related samples are domestication and foreignization translation strategies. The researchers tried to find out whether the translated samples are domesticated or foreignized.

\section{DATA ANALYSIS}

Here, the sample phrasal verb items are analyzed. These 10 items and their translations have been listed in a table comparatively. The translation strategy is also mentioned. The phrasal verbs are adapted from news websites such as http://press.blogfa.com, www.amnesty.org, www.huffingtonpost.com, www.en.wikipedia.org, www.marketwatch.com, www.bellenews.com, emonahansnewmexico.blogspot.com, http://richmondconfidential.org.

The phrasal verbs and their respective translations are analyzed bellow:

1. Three Vietnamese bloggers face up to 20 years in jail simply for exercising their right to freedom of expression.

The phrasal verb is face up is foreignized in the target language as بذيرفتن يا كنار/مدن بان

2. If someone wants to try and I feel up to it, I might even show them why I am right.

This phrasal verb, feel up to, is an instance of domestication in the target language. It is translated as حس و حال كارى داشتن

3. Presidential campaigns deceive political reporters all the time and often get away with it.

Get away with is domesticated in the Persian language and rendered as قنسر در رفنن

4. Socialism did not grow out of the pipe.

cannot be an appropriate foreignized equivalent for grow out of, since in this sentence, socialism cannot grow in size.

5. Their wages would not keep up with higher prices.

Keep up with is rendered as كفاف دادن which can be regarded as a kind of domesticated equivalent in Persian.

6. And you run into the same kind of mediocrity that you encounter anywhere else in life.

This phrasal verb, run into, is domesticated in the Persian language. Therefore, it is rendered as برخورد كردن، مواجه شدن

7. Anderson Cooper admitted on Friday that $\mathrm{CNN}$ had come across the late Ambassador

is the foreignized translation for the phrasal verb come across.

8. They will want to beef up their operations to make up for any slack.

Make up for is rendered as جبر/ن كردن which is an instance of domestication.

9. Peaceful demonstrations call for political reform.

Based on the above sentence, call for is domesticated and translated as خواستار شدن

10. Cut down on salt, sugar and fat.

كم كردن از Cut down on is domesticated and rendered as

\section{CONCLUSION}

Among the above analyzed items, seven ones have been domesticated by the translators while just three items show the application of foreignization translation strategy. Both strategies investigated in this paper have their own supporters. "Domestication designates the type of translation in which a transparent, fluent style is adopted to minimize the strangeness of the foreign text for target language readers, while foreignization means a target text is produced which deliberately breaks target conventions by retaining something of the foreignness of the original" (Shuttleworth \& Cowie 1997, p.59).

The different perspectives provided for or against domestication or foreignization translation strategies are various. Actually, both domestication and foreignization have their merits and demerits. Yang (2010) contends that readers can understand the translated meanings by domesticating translation. Foreignizing translation strategy keeps the source text "formal features and in turn informs the readers of the SL-culture, but alien cultural images and linguistic features may cause the information overload to the reader". Hence, both domestication and foreignization translation strategies involve losses which are unavoidable in translating.

As this paper proved, the translators tended to domesticate the phrasal verbs in news. Since phrasal verbs are mainly idiomatic phenomena and are consequently culture-specific, it may be claimed that domestication strategy could be more applicable to rendering such phenomena, as domestication strategy focuses more on the reader and target language text. 


\section{REFERENCES}

[1] Aal, W. H. (1994). The Role and future of Journalistic Translation. In Beaugrande, R, Shunnaq, Heliel, M. (1994) (Ed.). Language, Discourse and Translation in the West and Middle East. John Benjamins Publishing Company: Amsterdam and Philadelphia.

[2] Chen, L. (2010). On Integrated Translation Approach of English Idioms, Journal of Language Teaching and Research, Vol.1, No.3, pp.227-230.

[3] Chesterman, A. (2000). Translation in Context. Amesterdam and Philadelphia: John Benjamins Publications.

[4] Dongfeng, W. (2002), Domestication and Foreignization: a Contradiction? In China Translation, Vol.9, pp.24-26.

[5] Gambier, (Y). Transformations in International News in Conwa, K. \& Bassnett, S. (2006). (E.d). Translation in Global News, Proceedings of the conference held at the University of Warwick 23 June 2006. The Centre for Translation and Comparative Cultural Studies University of Warwick: U.K.

[6] Hatim,B. \& Munday,J. (2004). Translation an Advanced Resource Book. London: Routledge.

[7] Hart, W.C (2009). The Ultimate Phrasal Verb Book. New York: Barron's.

[8] Hori, M. Tabata, T. and Kumamoto, S (Ed.). Stylistics Studies of Literature. Germany: Peter Lang.

[9] Li, F. R. S. \& Xia, T. (2010). Translation of Words with Cultural Image. Journal of language Teaching and Research (5), pp.694-700.

[10] Munday, J. (2001) Introducing Translation Studies: Theories and applications, London \& New York: Routledge.

[11] Newmark, P. (1983). Paragraphs on Translation. Clevedon, Philadelphia and Adelaide: Multilingual Matters LTD.

[12] Nida, E. (1964). Toward a Science of Translating: With Special Reference to Principles and Procedures involved in Bible Translation, E.J. Brill, Leiden, Netherlands.

[13] Qi-min, C. (2010). On the Translation of Culture-Loaded Words in English News, Canadian Social Science, Vol.6, No.5, pp.164-168.

[14] Shuttleworth, M. \& M. Cowie. (1997). Dictionary of Translation Studies, Manchester, UK: St Jerome Publishing.

[15] Venuti, L. (1995). The Translator's Invisibility: A history of Translation, London \& New York, Routledge.

[16] Vybíralová, H. (2012). Journalistic Translation in the Selected Czech Press. Unpublished Master Thesis. Masaryk University: Czech.

[17] Yang, W. (2010). Brief Study on Domestication and Foreignization in Translation, Journal of Language Teaching and Research, Vol.1, No.1, pp.77-80.

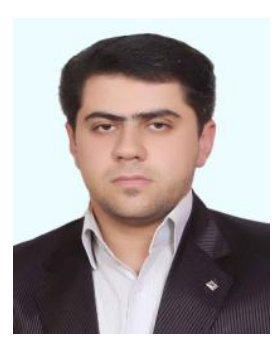

Ebrahim Davoudi Sharifabad is a PhD candidate of Translation in the School of Languages, Literacies, and Translation, Universiti Sains Malaysia. He has been a researcher and instructor of translation studies for some years in Iran. His field of specialization in translation studies is Translation Theories, Discourse Analysis and mainly translation and linguistics, namely linguistic issues of the Holy Qur' an and journalistic texts and their translations. As a translator, translation trainer and translation studies researcher, Davoudi Sharifabad has published some papers on the linguistic issues of translation.

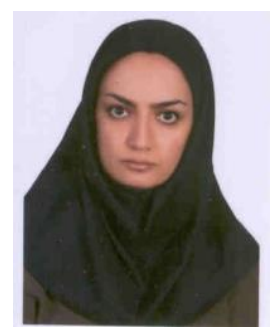

Mojde Yaqubi was born in 1986, Bijar, Iran. She studied English literature and English Translation at BA and MA degrees in Iran. Currently she is a PhD candidate of Translation Studies in the school of Humanities, Universiti Sains Malaysia since August 2011. Her fields of specialization in translation studies are 'transferring politeness aspects in translation', 'technical translation', and 'Translating conversational implicatures in Audiovisual Translation'. She is also interested in the field of 'terminology' and 'philology'.

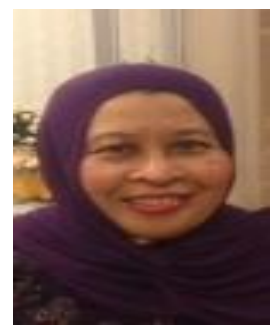

Tengku Sepora Tengku Mahadi is an Associate Professor in Translation. She got her PhD from the University of Surrey. U.K. She is the Deputy Dean of Academic and Student Development in the School of Languages, Literacies, and Translation, Universiti Sains Malaysia. As an Associate Professor in Translation and Translation Studies Researcher, she has published papers and supervised $\mathrm{PhD}$ and Master students' theses. Her field of specialization is Theory and Practice of Translation, Pragmatic Texts, Text Analysis, Legal Translation, Interpretation, English For Specific Purposes. 